\title{
O ensino de Biologia Celular e Molecular na formação inicial docente a partir do método Team-based-learning
}

\author{
The teaching of Cell and Molecular Biology in initial teacher education using the Team-based-learning \\ method
}

Karoline Schallenberger ${ }^{1}$, Natalia Aparecida Soares ${ }^{2}$

${ }^{1}$ Graduada do curso de Ciências Biológicas-Licenciatura, Instituto das Ciências da Saúde, Universidade Feevale, Novo Hamburgo, RS, Brasil.

${ }^{2}$ Docente do curso de Ciências Biológicas, Instituto das Ciências da Saúde, Universidade Feevale, Novo Hamburgo, RS, Brasil.

*e-mail: karoline.schallenberger@gmail.com

\section{Resumo}

As disciplinas de biologia celular e molecular são consideradas temáticas de alto teor abstrato e complexo para abordar no ensino médio, trazendo muitos desafios e insegurança para o futuro docente e dificultando o entendimento do conteúdo por parte dos alunos. Neste estudo investigou-se o ensino de Biologia Celular e Molecular na formação inicial docente, em um curso de licenciatura em Ciências Biológicas, diagnosticando saberes dos acadêmicos e as potenciais práticas pedagógicas com expressivo potencial para a abordagem do tema. O grupo amostral foi constituído por Licenciandos do curso de Ciências Biológicas de uma Universidade da região metropolitana de Porto Alegre/RS. Visando identificar as limitações ou fragilidades relativas a estas temáticas realizou-se uma coleta de dados inicial através de um questionário. Após, foi ministrada uma aula abordando os conceitos de menor domínio dos estudantes e em seguida separou-se a turma em grupos para aplicação da estratégia de team-based learning (TBL). A TBL demonstrou um resultado positivo quanto a interação dos acadêmicos durante a atividade, entretanto, revelou a fragilidade das disciplinas do núcleo de formação básica do licenciado em Ciências Biológicas. Compreendemos que a estrutura curricular da formação de docentes em Ciências Biológicas traz uma vasta listagem de conceitos e saberes docentes, entretanto, são necessários mais momentos de reflexão sobre a transposição didática dos conceitos que estão sendo assimilados.

Palavras-chave: (Aprendizagem baseada em equipes; Ensino de Ciências; Licenciatura)

\begin{abstract}
Cell and molecular biology are considered disciplines of high abstraction and complexity to be addressed in high school, bringing many challenges and insecurity for the future teacher and causing some difficulty in understanding the concepts by students. This study investigated the teaching of Cell and Molecular Biology in initial teacher education, in Biological Sciences Education course, diagnosing academic knowledge and pedagogical practices with significant potential for the approach the theme. The sample group consisted with undergraduate students in Biological Sciences Education course at a University in the metropolitan region of Porto Alegre/RS. To identify potential limitations or weaknesses in these themes, an initial data collection was performed. Subsequently, a class was taught approaching the concepts of less knowledge of the students and then the participants were separated into groups for the main moment of the team-based learning (TBL) strategy. The TBL showed a positive result regarding the interaction of academics during the activity, however, revealed the fragility of the basic education core disciplines of the Biological Sciences Education course. We understand that the curricular structure for the formation of teachers in Biological Sciences brings a wide list of concepts and teaching knowledge, however, more moments of reflection on the didactic transposition of the concepts that are being assimilated are needed.
\end{abstract}

Keywords: (Team-based learning; Science teaching; Teacher education) 
Introdução

Atualmente $\mathrm{o}$ ensino brasileiro pauta-se em dois principais documentos norteadores: os Parâmetros Curriculares Nacionais (PCN) e a Base Nacional Comum Curricular (BNCC). Ambos documentos foram desenvolvidos conforme a Lei de Diretrizes e Bases da Educação Nacional (LDB) - Lei n 9.394/1996, que norteia os currículos e as propostas pedagógicas de toda a educação básica brasileira.

Os PCN [1] do ensino médio foram propostos com o intuito de aprimorar a qualidade do ensino nesta modalidade, rompendo com a descontextualização e o excesso de conteúdos tão predominante no currículo. Contudo, os índices de qualidade da educação no ensino médio não se desenvolveram conforme o esperado pelas metas impostas, com isso, em 2010, na Conferência Nacional de Educação, especialistas discutiram sobre a necessidade da atualização das orientações curriculares nacionais.

Nesta perspectiva surge a BNCC visando unificar o ensino em todo o país e elevar os níveis da qualidade da educação, definindo diversas aprendizagens essenciais que os alunos devem desenvolver até o final da educação básica [2]. Neste documento, as competências e habilidades estão apresentadas na modalidade de currículo em espiral, englobando diferentes temáticas, as quais aparecem de forma mais generalista nos documentos norteadores. Em estudos realizados nestes documentos, encontrou-se menção a apenas uma habilidade que aborda o tema de biologia celular e molecular em todo o Ensino Médio.

Por outro lado, nos PCN de Ciências da Natureza, Matemática e suas Tecnologias encontrou-se 8 competências e habilidades relativas a biologia celular e 15 referentes ao ensino de biologia molecular, estas distribuídas em 9 temáticas conforme o quadro 1. 
Quadro 1. Temáticas encontradas nas Competências e Habilidades dos documentos norteadores.

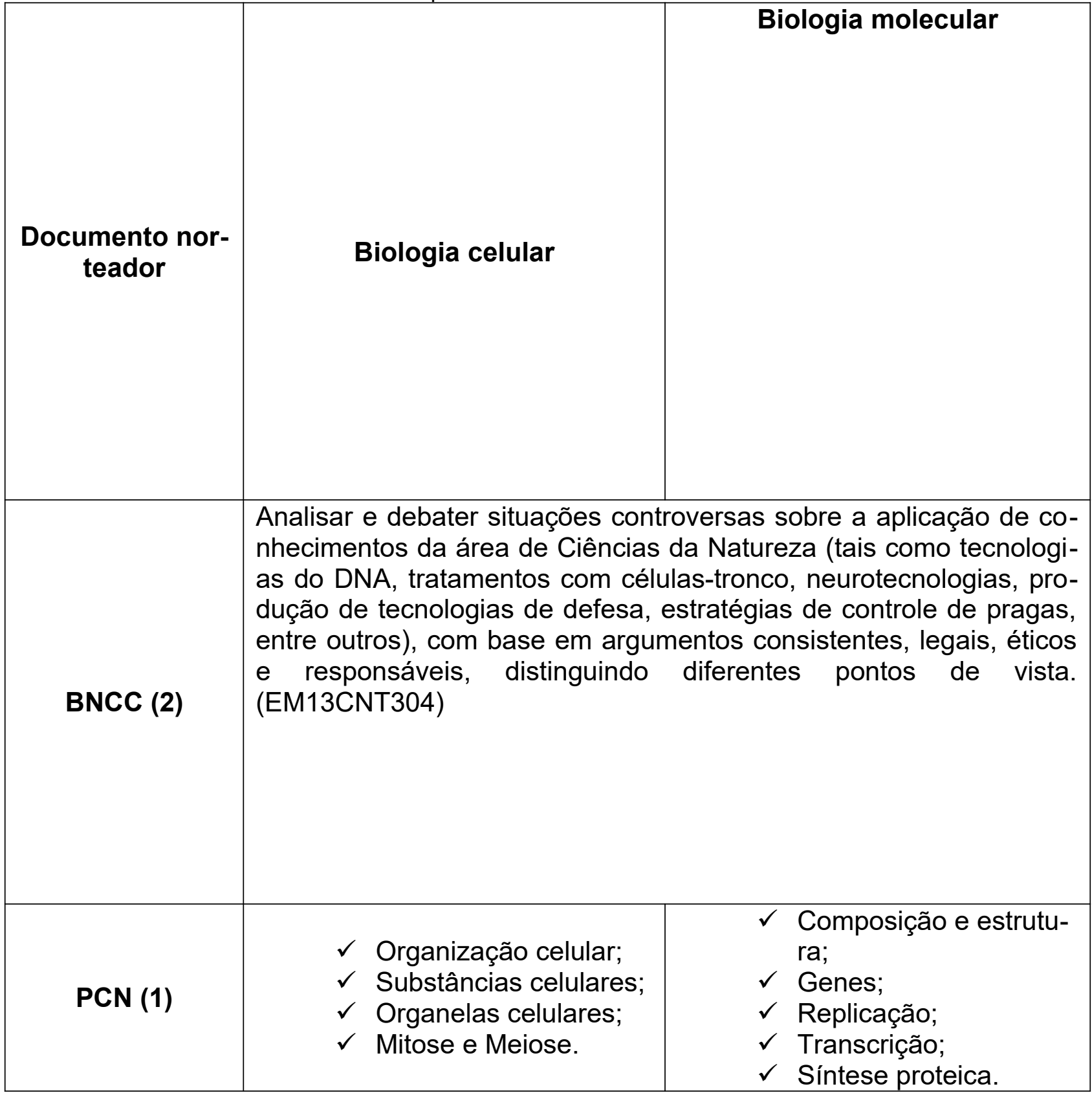

É possível observar no quadro 1 , que os PCN possuem uma proposição das temáticas mais conteudistas e segmentadas e que a BNCC apresenta uma visão mais globalizadora e em espiral, onde os conteúdos relacionam-se entre si através de temas geradores, competências e habilidades.

A disciplina de biologia celular e molecular é um componente curricular obrigatório nos cursos de ensino superior para formação de professores de Biologia. Constantes são os avanços nesta área do conhecimento, pois cada vez mais se buscam técnicas de aprimoramento e detecção genética. Devido ao teor abstrato e complexo dessas temáticas, os futuros professores não se sentem confortáveis para abordar temas da atualidade que envolvem a essência básica das disciplinas de biologia celular e molecular 
[3].

Em um estudo realizado por Jann e Leite [4], foi possível identificar que os alunos possuem o conhecimento conceitual de partes do conteúdo sobre Biologia Molecular, entretanto eles não compreendem totalmente aquela informação, consequentemente não conseguem entender sua aplicação. Através de um jogo didático realizado com o último ano do Ensino Médio, neste mesmo estudo, foi possível perceber que os estudantes conseguiram aplicar os conceitos e entender os processos de duplicação, transcrição, tradução e síntese proteica.

McClean et al [5] verificaram que através da utilização de animações 3D seguidas de explicações, os alunos obtiveram um melhor entendimento dos processos de transcrição, tradução, expressão gênica bacteriana, processamento de RNA mensageiro (mRNA), splicing de mRNA, transporte de proteína em uma organela, cadeia de transporte de elétrons e uso de um gradiente biológico para conduzir a síntese de adenosina trifosfato. Essa é uma estratégia que pode ser facilmente aplicada ao ensino das temáticas complexas, pois muitas vezes, o material didático do professor apresenta os processos somente em duas dimensões, dificultando a compreensão do procedimento que está ocorrendo.

Os modelos didáticos também representam estratégias que facilitam a exemplificação desta temática para os alunos. Conforme Orlando et al [6], essa metodologia auxiliou os estudantes na compreensão dos processos celulares, os quais se sentiram mais motivados e interessados nas temáticas de biologia celular e molecular. Esse interesse fez com que os alunos tivessem uma melhor assimilação e aprendizagem do conteúdo.

Melo e Carmo [7], constataram que poucos são os trabalhos relacionados ao ensino de Biologia Molecular no ensino médio, inclusive as pesquisas do tema em livros didáticos, que são a principal fonte de informação das escolas brasileiras. A falta de estudo nesta área pode estar relacionada a falta de preparo dos docentes de Biologia. Diante disso, observou-se que a dificuldade para ministrar temáticas relativas a biologia celular e molecular é recorrente e, portanto, são necessárias ações de formação continuada e atualização dos professores.

As metodologias ativas são estratégias de ensino que permitem a inserção dos alunos como protagonistas das discussões, facilitando o entendimento e a transformação das informações em conhecimento. Essa metodologia tem a característica de ser multidisciplinar, já que permite a retomada de outros conceitos desenvolvidos em outras 
áreas do conhecimento [8].

Herzer et al [9] constatou que os acadêmicos têm maior consciência do processo de ensino e aprendizagem quando são utilizadas estratégias de metodologias ativas em aulas do ensino superior. Além disso, os alunos entendem como uma simulação da vida profissional as atividades desenvolvidas através da metodologia, sendo o momento de colocar em prática todos os conhecimentos adquiridos ao longo da graduação antes de ingressar ao mercado de trabalho.

A estratégia de aprendizagem baseada em equipes (ABE), do inglês Team-based learning (TBL), é um método de ensino ativo que engloba uma sequência de atividades, a partir do desenvolvimento conceitual individual, seguido do trabalho em equipe para desenvolvimento de alguma situação e por final uma atividade de feedback [10]. Essas atividades instigam o conhecimento individual dos alunos, de forma à promover e desenvolver a ligação dos conceitos aprendidos em conhecimento.

Com isso, o objetivo deste trabalho foi investigar os saberes acadêmicos e potenciais práticas pedagógicas com expressivo potencial para a abordagem do Ensino de Biologia Molecular na formação inicial docente, em um curso de Licenciatura em Ciências Biológicas.

\section{Metodologia}

O grupo amostral deste estudo constitui-se por acadêmicos $(n=13)$ matriculados na disciplina que antecede o estágio docente em Biologia, ofertado em um curso de licenciatura em ciências biológicas de uma Universidade situada na região metropolitana de Porto Alegre/RS. Os participantes deste estudo receberam esclarecimentos referentes aos objetivos e métodos da pesquisa e manifestaram-se cientes por meio de um Termo de Consentimento Livre e Esclarecido.

A coleta dos dados realizou-se no segundo semestre do ano de 2019. Para atender ao objetivo deste trabalho, utilizou-se a estratégia de aprendizagem baseada em equipes $(A B E)$, onde em um primeiro momento foi aplicado um questionário semiestruturado aos acadêmicos. Essa estratégia foi composta por quatro etapas distintas, conforme apresentado na figura 1. 
Coleta de dados inicial

Dados sociodemográficos;

Nível de confiança com as temáticas;

Fatores que promovem maior confiança na docência

\section{Preparação}

Exposição acerca das temáticas:

Biologia Celular, Biologia Molecular, Células tronco, Transgênicos, Terapia Gênica.

\section{Situações} problemas

Planejar uma aula sobre células tronco;

Planejar uma aula sobre transgênicos;

Planejar uma aula sobre terapia gênica.
Socialização

Apresentação em forma de cartazes; Diálogo com a tur-ma referente às estratégias adota-das pelos grupos.

Figura 1. Etapas do desenvolvimento da estratégia de aprendizagem baseada em equipes.

Para conhecimento do público deste estudo, foram coletados os dados sociodemográficos, com informações sobre o sexo, idade, semestre que está cursando e o tempo de experiência docente. Utilizou-se a escala de mensuração de atitude [11] para verificar o quanto os acadêmicos se sentem confortáveis em abordar as temáticas referentes ao ensino de biologia celular e molecular no Ensino Médio (quadro 1).

Quadro 1. Escala de mensuração do nível de confiança em abordar os temas referentes ao ensino de biologia celular e molecular no ensino médio.

\begin{tabular}{|r|ccccc|}
\hline Conteúdo & $\begin{array}{c}\mathbf{1} \\
\text { Nada } \\
\text { confiante }\end{array}$ & $\begin{array}{c}\mathbf{2} \\
\text { Pouco } \\
\text { confiante }\end{array}$ & $\begin{array}{c}\mathbf{3} \\
\text { Confian- } \\
\text { te }\end{array}$ & $\begin{array}{c}\mathbf{4} \\
\text { Muito } \\
\text { confiante }\end{array}$ & $\begin{array}{c}\mathbf{5} \\
\text { Totalmente } \\
\text { confiante }\end{array}$ \\
\hline Teoria Celular & 0 & 0 & 0 & 0 & 0 \\
\hline Organelas & 0 & 0 & 0 & 0 & 0 \\
\hline Osmose & 0 & 0 & 0 & 0 & 0 \\
\hline Mitose e Meiose & 0 & 0 & 0 & 0 & 0 \\
\hline Histologia & 0 & 0 & 0 & 0 & 0 \\
\hline DNA & 0 & 0 & 0 & 0 & 0 \\
\hline RNA & 0 & 0 & 0 & 0 & 0 \\
\hline Síntese proteica & 0 & 0 & 0 & 0 & 0 \\
\hline Células tronco & 0 & 0 & 0 & 0 & 0 \\
\hline Terapia gênica & 0 & 0 & 0 & 0 & 0 \\
\hline Clonagem & 0 & 0 & 0 & 0 & 0 \\
\hline Transgênicos & 0 & 0 & 0 & 0 & 0 \\
\hline
\end{tabular}

Objetivando verificar o grau de importância atribuído pelos acadêmicos aos fatores que influenciam no nível de confiança para abordar os conteúdos relacionados a biologia celular e molecular em uma aula de biologia para o Ensino Médio, propôs-se uma escala 
conforme o quadro 2.

Quadro 2. Escala de mensuração do nível de importância dos fatores que promovem uma maior confiança para abordar os conteúdos relacionados a biologia celular e molecular em uma aula para o Ensino Médio.

\begin{tabular}{|c|c|c|c|c|c|}
\hline Fator & $\begin{array}{c}1 \\
\text { Sem impor- } \\
\text { tância }\end{array}$ & $\begin{array}{c}2 \\
\text { Pouco im- } \\
\text { portante }\end{array}$ & $\begin{array}{c}3 \\
\begin{array}{c}\text { Supostamente } \\
\text { importante }\end{array}\end{array}$ & $\begin{array}{c}4 \\
\text { Importante }\end{array}$ & $\begin{array}{c}5 \\
\text { Muito im- } \\
\text { portante }\end{array}$ \\
\hline $\begin{array}{r}\text { Meu nível de conheci- } \\
\text { mento }\end{array}$ & O & O & O & O & O \\
\hline $\begin{array}{r}\text { Aulas práticas durante } \\
\text { a minha formação }\end{array}$ & O & O & O & ○ & ○ \\
\hline $\begin{array}{r}\text { Participação em proje- } \\
\text { to de extensão }\end{array}$ & 0 & O & O & ○ & ○ \\
\hline Formação continuada & O & o & O & O & O \\
\hline $\begin{array}{l}\text { Recursos audiovisuais } \\
\text { disponíveis na escola }\end{array}$ & O & O & O & O & O \\
\hline Livros & O & O & O & O & O \\
\hline Reportagens & o & o & 0 & o & o \\
\hline $\begin{array}{r}\text { Modelos de aula práti- } \\
\text { ca na internet }\end{array}$ & 0 & 0 & 0 & 0 & 0 \\
\hline $\begin{array}{r}\text { Jogos didáticos dispo- } \\
\text { níveis }\end{array}$ & O & O & O & O & 0 \\
\hline
\end{tabular}

Posteriormente, realizou-se a etapa de preparação do grupo amostral, através de uma aula expositiva e dialogada com o uso de modelos didáticos e uma explicação metodológica de como é feita essa aplicação no meio científico, foram relembrados conceitos de biologia celular e molecular. Estes temas emergiram dos resultados obtidos no instrumento de coleta inicial, considerados pelos acadêmicos como o menor nível de confiança para abordar em sala de aula as respectivas temáticas.

Após o desenvolvimento da aula com duração de duas horas, a turma foi separada em três equipes aleatórias, com o objetivo de desfazer os grupos de afinidades e aplicar a terceira etapa denominada como aplicação. Para tal, foi entregue uma situação problema para cada grupo, onde cada uma abordava um dos temas explicados em aula, e mencionados na coleta inicial como menor nível de confiança para abordar nas aulas de Biologia no Ensino Médio. A partir destas situações problemas, foi solicitado que os acadêmicos desenvolvessem uma sequência didática para abordar a temática, conforme o quadro abaixo. 
Quadro 3. Situações problemas utilizadas com os grupos de acadêmicos para elaborarem uma aula, seguindo as temáticas que eles indicaram menor segurança em abordar.

\begin{tabular}{|c|c|}
\hline Temática & Situação problema \\
\hline Transgênicos & $\begin{array}{l}\text { Imagine você como professora titular de Biologia no Ensino Médio, o assunto que estás } \\
\text { trabalhando é Genética, eis que um aluno pergunta o que é um alimento transgênico, } \\
\text { afinal esse é um tema que está em alta na mídia, principalmente em relação a } \\
\text { obrigatoriedade de apresentar o símbolo de transgênico nas embalagens que } \\
\text { contenham alimentos com essa característica. Com a dúvida desse aluno, percebeu-se } \\
\text { uma divisão bem clara entre os alunos que defendiam o consumo dos transgênicos } \\
\text { contra os que acreditavam não ser uma boa escolha, opiniões fundadas através de } \\
\text { mídias acessadas pelos alunos. } \\
\text { Verificando essas divergências de opiniões, você percebe a deixa para trabalhar um } \\
\text { pouco mais aprofundado esse assunto sobre transgênicos, já que percebeu que os } \\
\text { alunos se interessaram de fato pela temática. Com isso, seu grupo deverá elaborar uma } \\
\text { sequência didática, que contenha as quatro etapas de uma boa aula, sobre } \\
\text { transgênicos. Lembrem de diversificar as estratégias de ensino, já que seus alunos se } \\
\text { mostraram motivados em aprender sobre essa temática. }\end{array}$ \\
\hline Células tronco & $\begin{array}{l}\text { Imagine você como professora titular de Biologia no Ensino Médio, o assunto que estás } \\
\text { trabalhando é Citologia, eis que um aluno traz um livro que está utilizando para estudar } \\
\text { para o ENEM com algumas questões sobre células tronco e pede ajuda sobre como } \\
\text { respondê-las. Com a dúvida desse aluno, percebeu-se diversas curiosidades sobre o } \\
\text { tema entre o restante dos alunos da turma. } \\
\text { Verificando esse interesse dos alunos, você percebe e deixa para trabalhar um pouco } \\
\text { mais aprofundado esse assunto sobre células tronco. Com isso, seu grupo deverá } \\
\text { elaborar uma sequência didática, que contenha as quatro etapas de uma boa aula, } \\
\text { abordando essa temática. Lembrem de diversificar as estratégias de ensino, já que seus } \\
\text { alunos se mostraram motivados em aprender sobre células tronco. }\end{array}$ \\
\hline Terapia gênica & $\begin{array}{l}\text { Imagine você como professora titular de Biologia no Ensino Médio, recentemente seus } \\
\text { alunos visitaram uma feira de ciências e viram um trabalho de pesquisa que trazia } \\
\text { alguns dados sobre um caso de terapia gênica em crianças portadoras de atrofia } \\
\text { muscular espinhal do tipo } 1 \text {, uma doença genética caracterizada pela atrofia progressiva } \\
\text { dos músculos esqueléticos e morte precoce antes dos } 2 \text { anos de idade. A doença é } \\
\text { causada por um gene defeituoso, que deixa de codificar uma proteína essencial para o } \\
\text { funcionamento dos neurônios. No estudo, vírus não patogênicos que continham uma } \\
\text { cópia normal do gene em questão foram injetados em quinze crianças doentes, } \\
\text { prolongando a expectativa de vida destas crianças. Ao voltarem para a escola, } \\
\text { questionaram a professora de Biologia como era possivel ocorrer isso. } \\
\text { Verificando esse interesse dos alunos, você percebe a deixa para trabalhar um pouco } \\
\text { mais aprofundado esse assunto sobre terapias gênicas, tendo em vista que você está } \\
\text { trabalhando os conteúdos de material genético e aplicações de biologia molecular. Com } \\
\text { isso, seu grupo deverá elaborar uma sequência didática, que contenha as quatro etapas } \\
\text { de uma boa aula, abordando essa temática. Lembrem de diversificar as estratégias de } \\
\text { ensino, já que seus alunos se mostraram motivados em aprender sobre terapia gênica. }\end{array}$ \\
\hline
\end{tabular}

Com o término dessa atividade, promoveu-se a quarta etapa da coleta de dados, onde os estudantes socializaram as estratégias propostas para resolver o problema apresentado e planejaram a sequência didática. Os acadêmicos apresentaram em formato de cartazes, mas durante a apresentação foram feitas considerações sobre o que eles haviam desenvolvido, avaliando se a troca de conhecimentos durante a resolução dos problemas desenvolveu novas ideias para os acadêmicos abordarem as temáticas mais complexas sobre biologia celular e molecular.

Essa estratégia de aprendizagem baseada em equipes tem como característica promover uma discussão sobre as concepções dos participantes, permitindo que os alunos troquem conhecimentos e percepções sobre as temáticas. Desenvolvendo assim a 
autoafirmação sobre o conteúdo proposto e promovendo uma maior assimilação dos conteúdos que são trabalhados em aula [12].

\section{Resultados e discussão}

O questionário inicial foi aplicado com 13 acadêmicos que estavam presentes na disciplina onde ocorreu a coleta de dados do trabalho. Dos acadêmicos presentes, houve uma maior predominância de mulheres (77\%), sendo que a maioria estava na faixa etária de até 24 anos (62\%), seguido de 31 a 40 (23\%) e 25 a 30 anos (15\%). A maioria dos estudantes encontram-se entre o $6^{\circ}$ e o $7^{\circ}$ semestre $(77 \%)$ e apenas dois mencionaram ter experiência docente, um de 4 anos e outra aluna com 2 meses de estágio docente não obrigatório.

$\mathrm{Na}$ questão sobre o nível de domínio dos acadêmicos, conforme a figura 2, verificou-se que a maioria se considerou confiante para trabalhar assuntos como DNA, RNA, e divisão celular. Por outro lado, observou-se que, no que se refere à aplicação da teoria nas técnicas empregadas em biologia molecular, estes acadêmicos já não se sentiam tão confiantes para trabalhar esse assunto com os alunos de ensino médio.

Notoriamente observa-se que os acadêmicos se sentem muito confiantes para abordar as temáticas de DNA e RNA, entretanto, no item de bases nitrogenadas, que são os principais constituintes das moléculas genéticas, os acadêmicos não se sentiam confiantes para essa abordagem. Demonstrando que o conceito não está tão claro para estes alunos devido à complexidade da temática e aos diversos termos científicos empregados [6]. Essa é uma característica, também já observada em outro estudo, onde os estudantes afirmam conhecer as definições, mas não possuem uma organização das ideias e aplicações dos conteúdos que perpassaram em sua formação [13]. 


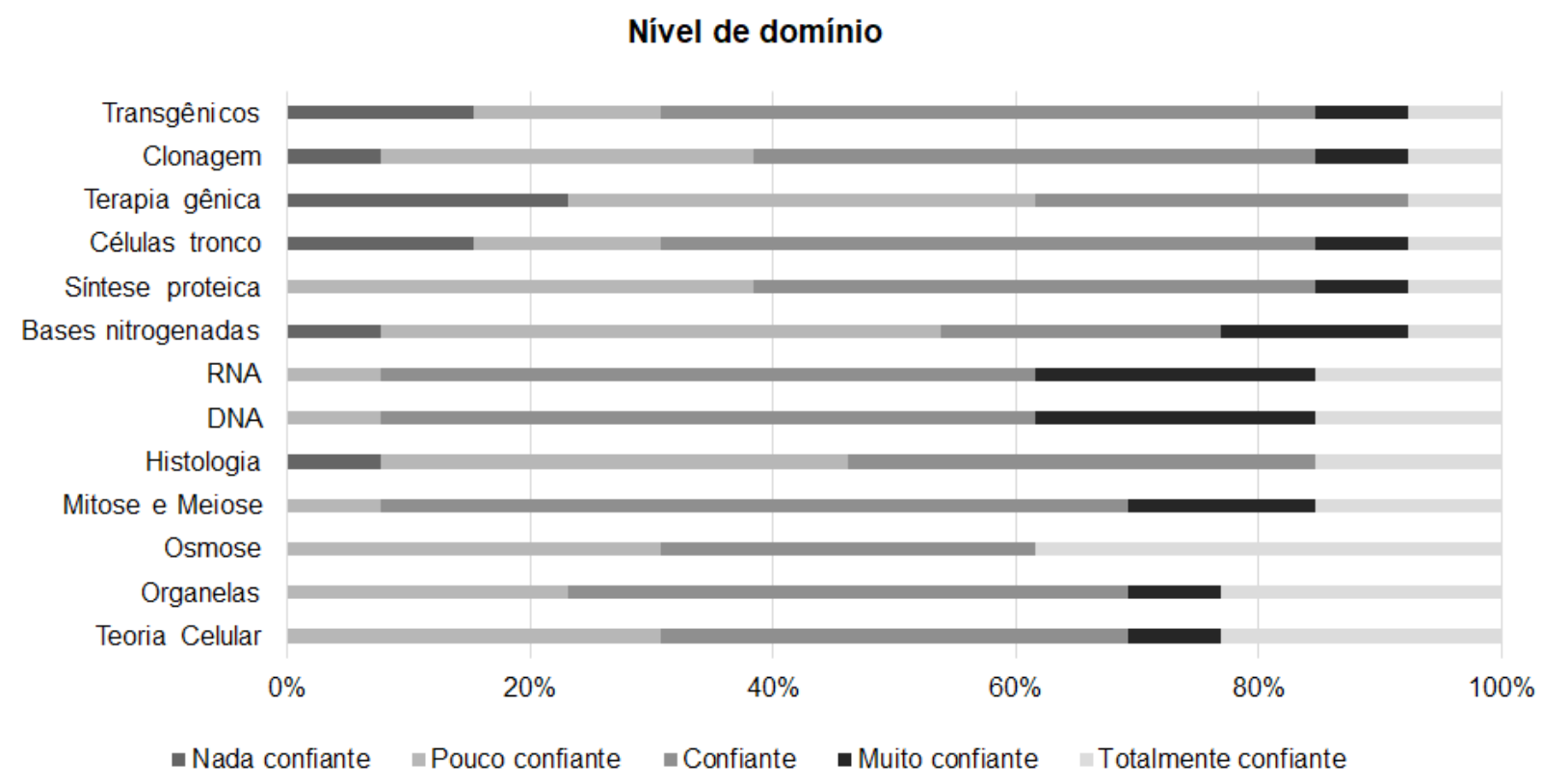

Figura 2. Resultados do nível de domínio dos acadêmicos nas temáticas referentes ao ensino de biologia celular e molecular para o ensino médio.

$\mathrm{Na}$ figura 3, que se refere ao grau de importância atribuído pelos acadêmicos aos fatores que influenciam no nível de confiança para abordar os conteúdos relacionados a biologia celular e molecular em uma aula de biologia para o Ensino Médio, atribuiu-se respectivamente uma maior importância ao domínio de conteúdo, aulas práticas durante a graduação, formação continuada e recursos audiovisuais disponíveis na escola.

\section{Fatores de influência na prática docente}

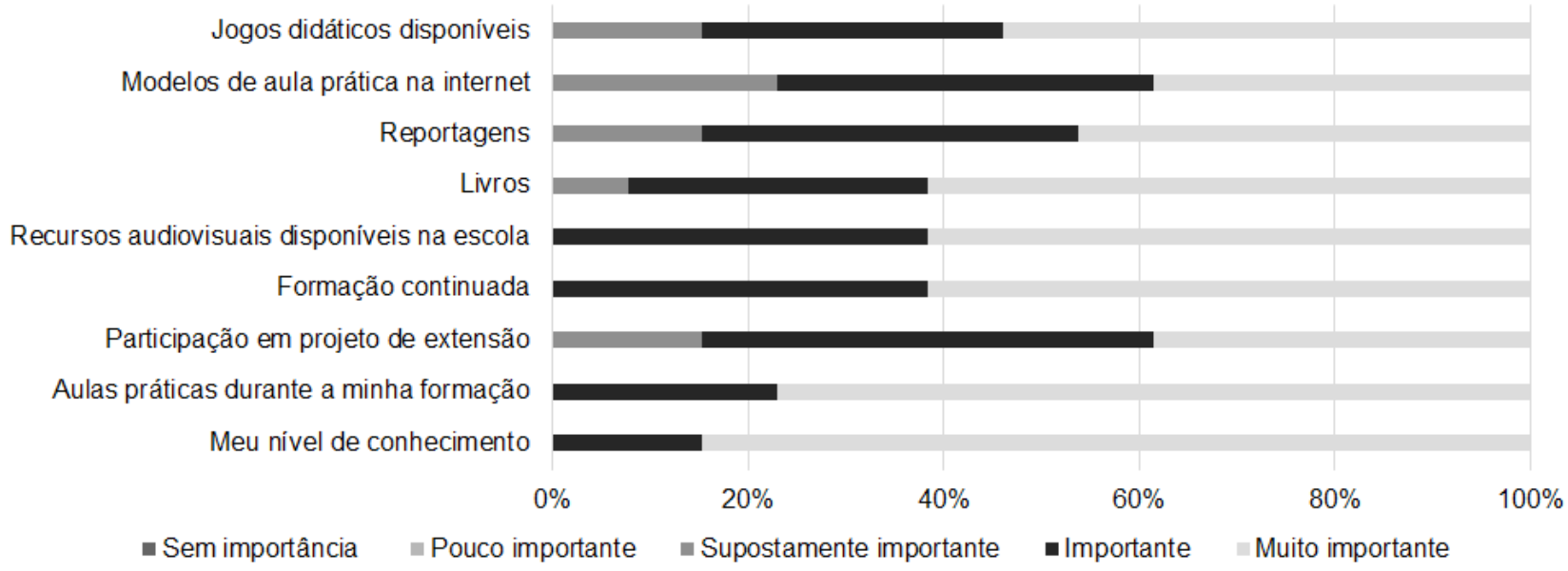

Figura 3. Grau de importância atribuído pelos acadêmicos aos fatores que influenciam no nível de confiança para abordar os conteúdos relacionados a biologia celular e molecular em uma aula de biologia para o Ensino Médio.

As temáticas que os acadêmicos não se sentiram nada confiante para abordar em uma aula de biologia no ensino médio, conforme instrumento de coleta inicial, foram: Terapia Gênica (23\%), Células tronco e Transgênicos (ambos 15\%). Com isso, para a etapa de preparação foram utilizados os conceitos descritos, e com base nestes foram 
organizadas as situações problemas.

Durante a preparação, onde apresentou-se através de uma aula expositiva e dialogada os principais conceitos relativos à temática, os acadêmicos interagiram timidamente colocando-se no papel de mero ouvintes. Nesta mesma etapa, mediante a apresentação de modelo didáticos representando a cromatina, um cromossomo e a montagem de uma proteína, conforme a figura 4, para abordar o tema, observou-se um maior envolvimento dos acadêmicos, através de questionamentos e curiosidades relativos aos recursos apresentados. Na terceira etapa, onde a turma foi dividida em grupos e cada um recebeu uma situação problema, os acadêmicos se mostraram mais interativos com a atividade.
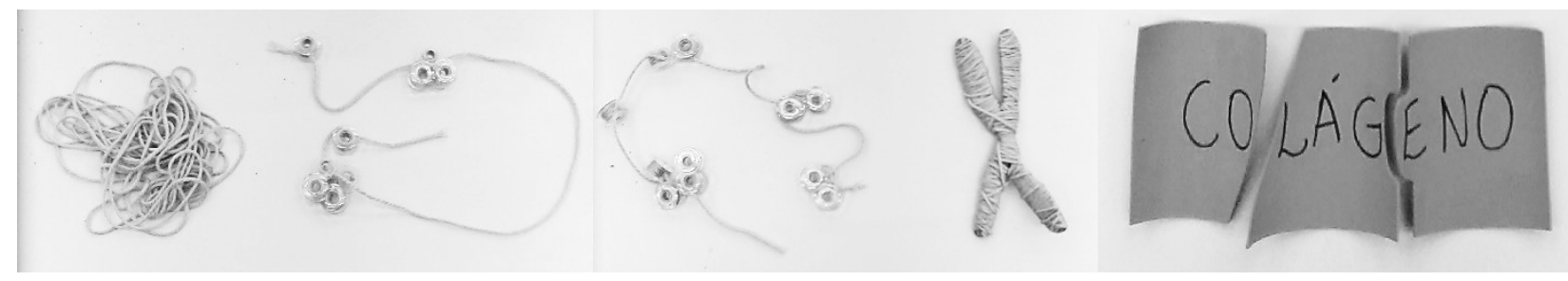

Figura 4. Modelos didáticos da cromatina, cromossomo e montagem de proteína.

Os acadêmicos apresentaram as sequências didáticas em forma de cartazes, representados pela figura 5, onde cada quadro vertical apresenta uma etapa da aula, iniciando com a introdução e retomada dos saberes, seguido da construção e posterior consolidação do conhecimento, por último a fixação e feedback [14].
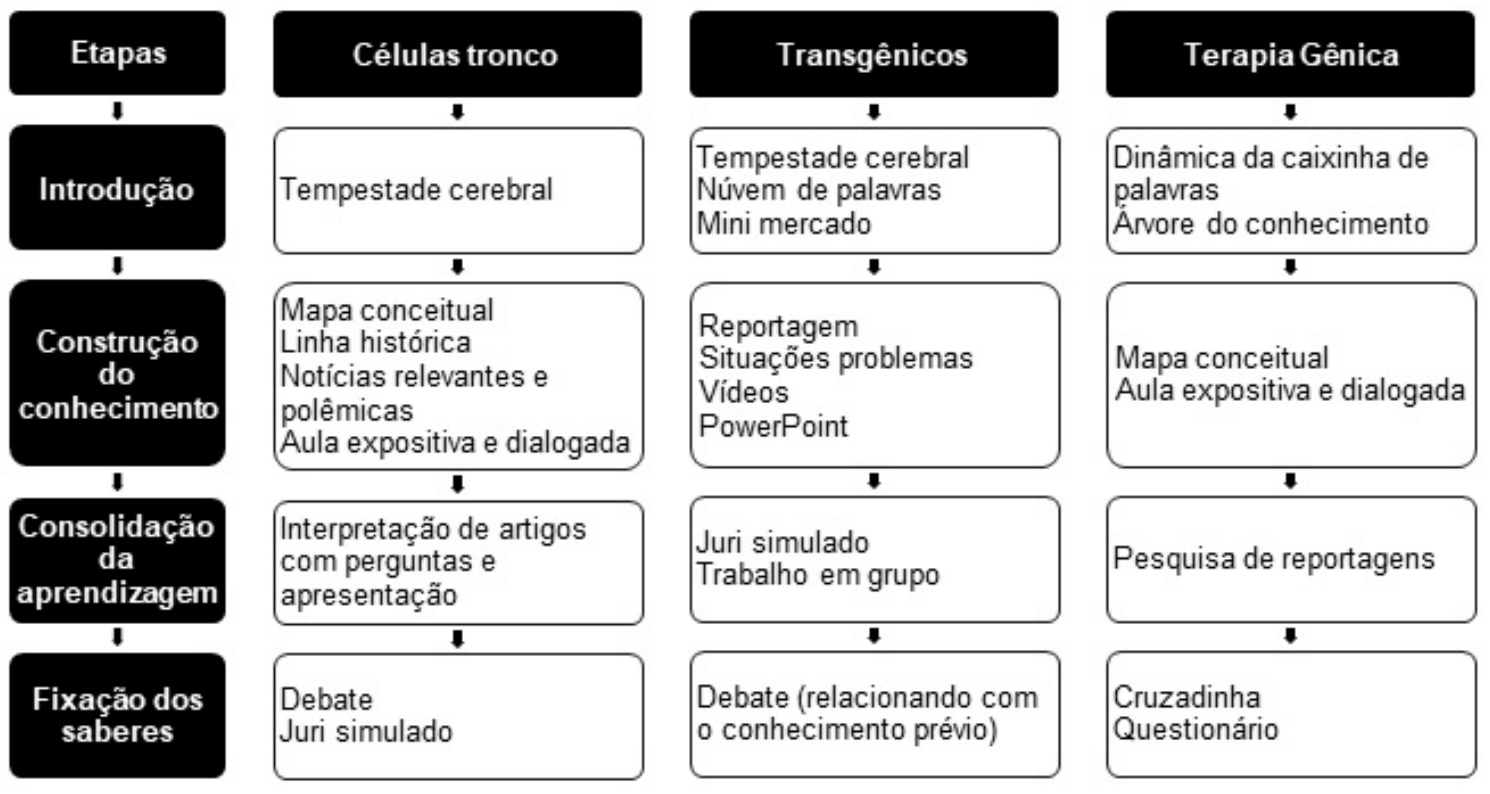

Figura 5. llustração das estratégias propostas nas sequências didáticas em forma de cartaz pelos grupos, conforme solicitado na situação problema.

Durante a última etapa, de socialização das estratégias empregadas para a 
solução da situação problema, dois grupos falaram em uso de artigos científicos e reportagens visando promover a alfabetização científica. Esse é um termo empregado com o objetivo de inserção dos alunos na ciência, e consequentemente na cultura científica [15]. Possibilitar o contato do estudante à ciência permite a formação de valores perante a sociedade e à tomada de decisões voltadas ao meio ambiente, qualidade de vida e resoluções de problemas atuais da sociedade [16].

Visando correlacionar as estratégias propostas pelos acadêmicos aos dados do questionário inicial, constatou-se que estes consideraram as aulas práticas como o segundo fator mais importante para a segurança na abordagem de determinada temática, conforme apresentado na figura 6. Entretanto, nas estratégias apresentadas na última etapa, nenhum grupo propôs como ferramenta uma aula prática para abordar o tema.

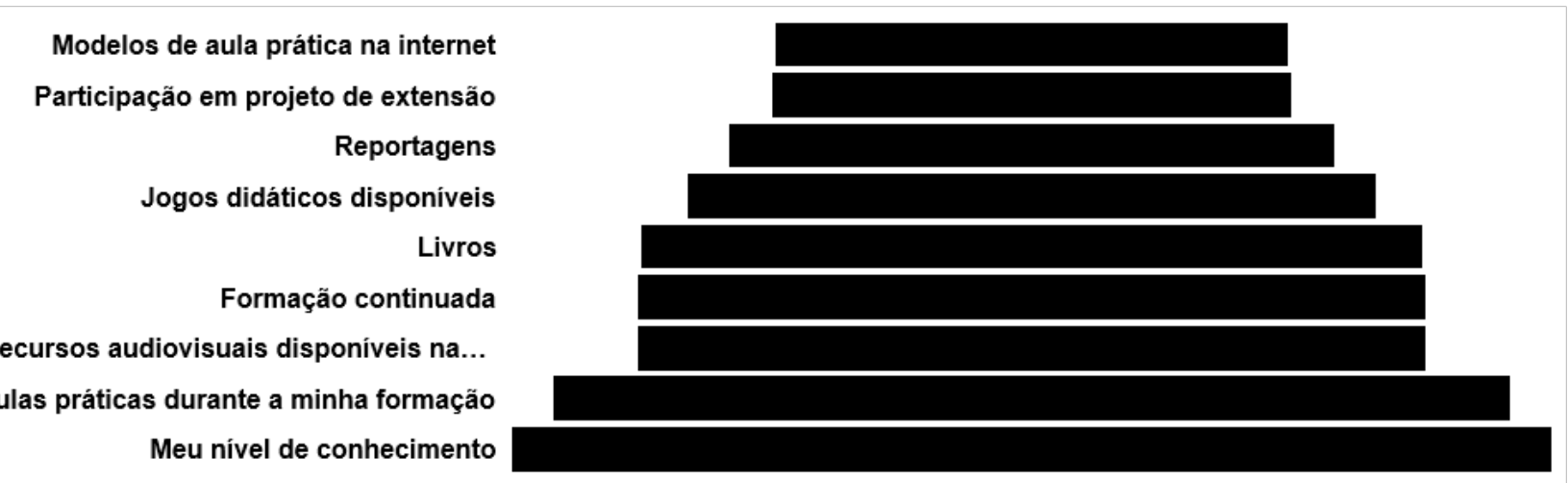

Figura 6. Pirâmide indicando o grau de importância dos fatores, definidos pelos acadêmicos no instrumento de coleta de dados inicial.

Em um estudo comparativo, realizado em turmas de biologia no Ensino Médio, onde verificou-se o desempenho de turmas em que o professor realizou aulas práticas e onde não houve a utilização dessa estratégia, percebeu-se que os alunos apresentaram um maior desempenho quando colocaram em prática o conteúdo que estava sendo trabalhado [17]. No entanto, em outro estudo que verificou a opinião de docentes em formação sobre o uso de aulas práticas no ensino de biologia, os acadêmicos consideraram importante, contudo não conseguiam relacionar e aplicar as aulas práticas durante a sua formação para os seus alunos nas escolas de nível básico [18].

O item "participação em projetos de extensão" recebeu um baixo nível de importância comparado ao "meu nível de conhecimento", nos fatores que influenciam o ensino. Outras pesquisas trazem os projetos de extensão como um laboratório para a prática do ensino, possibilitando desempenhar as estratégias vistas em teoria e transformando-as em práxis docente $[19,20]$.

As reportagens foram o terceiro fator com menor grau de importância listado pelos acadêmicos, contudo todos os grupos utilizaram essa estratégia na sequência didática. 
Essa pode ser outra forma de inserir a divulgação científica no Ensino Médio, com o uso de uma linguagem mais popular. Essa estratégia pode servir como um meio motivador para o ensino das temáticas propostas, visto que traz o aluno para alguma questão que está sendo discutida atualmente pela sociedade [21].

Do mesmo modo, observou-se que dois grupos apresentaram como estratégia o júri simulado e o debate, onde durante a socialização falou-se no desenvolvimento no potencial do ensino de biologia para auxiliar os discentes a desenvolver juízo de valor, formação de opinião e pensamento crítico por parte dos alunos de Ensino Médio. Os temas propostos possuem essa característica de fomentar discussões entre os acadêmicos, onde cada um expõe sua bagagem cultural. Através dessa estratégia proposta pelos acadêmicos, é possível trabalhar diversas habilidades de formação de cidadãos conscientes e com capacidade de defesa de suas ideias, tomada de decisão, julgamento e argumentação [22].

Alguns estudos utilizaram essa estratégia para abordar os temas socioambientais controversos, onde os estudantes já estavam com uma opinião formada e com a discussão de outros critérios envolvidos eles puderam repensar e ponderar suas opiniões [23]. Essas atividades retiram os alunos de suas zonas de conforto e os tornam protagonistas de suas aprendizagens [24].

As temáticas solicitadas nas situações problemas são referentes a assuntos polêmicos, que podem trazer algumas divergências de opiniões na turma, entretanto os acadêmicos trouxeram diversas estratégias para contornar esse viés. Os alunos precisam dessas vivências em sala de aula, pois devem estar preparados para debater e posicionar-se sobre os diferentes assuntos que são fontes de tantas opiniões divergentes, muitas vezes por falta de conhecimento argumentativo [25, 26].

\section{Considerações finais}

Este trabalho teve como objetivo investigar os saberes acadêmicos e potenciais práticas pedagógicas com expressivo potencial para a abordagem do ensino de biologia celular e molecular na visão dos acadêmicos em formação inicial docente, em um curso de Licenciatura em Ciências Biológicas.

A estratégia de aprendizagem baseada em equipes oportunizou a interação dos acadêmicos durante a proposição das estratégias de ensino, facilitando a troca de conhecimentos com o objetivo de montar sequências didáticas favoráveis ao ensino das temáticas propostas. Entretanto, revelou a fragilidade dos cursos de formação inicial de professores nas disciplinas do núcleo de formação básica do licenciado em ciências 
biológicas.

Pode-se notar divergências nos dados obtidos pela pesquisa, onde os acadêmicos demonstraram um perfil diferente conforme o instrumento de coleta. Essa característica foi observada na indicação de domínio dos conceitos, entretanto, na aplicação dos mesmos, revelaram sua dificuldade em entender os conceitos que estão reproduzindo. Esse é o principal aspecto que impossibilita ou dificulta a transposição didática na prática docente.

Desta forma, compreendemos que a estrutura curricular da formação de docentes em ciências biológicas traz uma vasta lista de conceitos e saberes docentes, entretanto, são necessários mais momentos que oportunizem aos acadêmicos a refletir sobre a transposição didática dos conceitos que estão sendo assimilados.

\section{Referências}

[1] BRASIL. Ministério da Educação. Orientações Educacionais Complementares aos Parâmetros Curriculares Nacionais para o Ensino Médio - PCN+. 2002a. Ciências da Natureza, Matemática e suas Tecnol Brasília, DF, [Internet]. 2002; Available http://portal.mec.gov.br/seb/arquivos/pdf/CienciasNatureza.pdf

[2] BRASIL. Base Nacional Comum Curricular: Ensino Médio. Ministério da Educ [Internet]. 2018; Available http://basenacionalcomum.mec.gov.br/images/historico/BNCC_EnsinoMedio_embaixa_site_110518.pdf

[3] Camargo SS, Infante-Malachias ME, Amabis JM. O Ensino De Biologia Molecular Em Faculdades E Escolas Médias De São Paulo. Rev Ensino Bioquímica. 2007;5(1):1.

[4] Jann PN, Leite MDF. Jogo do DNA: um instrumento pedagógico para o ensino de ciências e biologia. Ciências e Cognição. 2010;15(1):282-93.

[5] McClean P, Johnson C, Rogers R, Daniels L, Reber J, Slator BM, et al. Molecular and cellular biology animations: Development and impact on student learning. Cell Biol Educ. 2005;4(SUMMER):169-79.

[6] Orlando TC, Lima AR, Silva AM da, Fuzissaki CN, Ramos CL, Machado D, et al. Planejamento, Montagem E Aplicação De Modelos Didáticos Para Abordagem De Biologia Celular E Molecular No Ensino Médio Por Graduandos De Ciências Biológicas. Rev Ensino Bioquímica. 2009;7(1):1.

[7] Melo JR de, Carmo EM. Investigações sobre o ensino de Genética e Biologia Molecular no Ensino Médio brasileiro: reflexões sobre as publicações científicas. Ciência Educ. 2009;15(3):592-611.

[8] Melo B, Sant'Ana G. A prática da Metodologia Ativa. Com Ciências Saúde [Internet]. 2012;23(4):327-39. Available at: http://bvsms.saude.gov.br/bvs/artigos/pratica_metodologia_ativa.pdf \%0Ahttp://bvsms.saude.gov.br/bvs/artigos/pratica_metodologia_ativa.pdf\%0Ahttp://www.escs.edu.br/ pesquisa/revista/2012Vol23_4_5_ApraticaMetodologiaAtival.pdf

[9] Herzer M, Menezes FM. Avaliação da utilização de metodologias ativas no ensino superior: estudo de caso da disciplina de gestão da produção aplicada. J Chem Inf Model. 2013;53(9):1689-99.

[10] Parmelee D, Michaelsen LK, Cook S, Hudes PD. Team-based learning: A practical guide: AMEE Guide No. 65. Med Teach. 2012;34(5).

[11] Salkind N. "Technique for the Measurement of Attitudes, A". In: Encyclopedia of Research Design. 2012. 
[12] Koles PG, Stolfi A, Borges NJ, Nelson S, Parmelee DX. The impact of team-based learning on medical students' Academic Performance. Acad Med. 2010;85(11):1739-45.

[13] Vigario AF, Cicillini GA. Os saberes e a trama do ensino de Biologia Celular no nível médio Knowledge forms and the plot of Cell Biology teaching in high school. 2019;57-74.

[14] Vasconcellos C dos S. Coordenação do Trabalho Pedagógico: do trabalho políticopedagógico ao cotidiano da sala de aula. 2002.

[15] Sasseron LH, Maria A, Carvalho $P$ De. Alfabetização científica: uma revisão bibliográfica. 2011;16(1):59-77.

[16] Chassot A. Alfabetização científica: uma possibilidade para a inclusão social. 2002;157-8.

[17] De Lima DB, Garcia RN. Uma investigação sobre a importância das aulas práticas de Biologia no Ensino Médio. Cad do Apl. 2011;24(1).

[18] Duré RC, Abílio FJP. A Formação Inicial na Concepção Docente: Um Estudo Fenomenológico com Professores de Ciências Biológicas. Rev Bras Pesqui em Educ em Ciências. 2019;345-71.

[19] Pereira dos Santos M. Extensão Universitária: Espaço de Aprendizagem Profissional e Suas Relações com o Ensino e a Pesquisa na Educação Superior. Extensio Rev Eletrônica Extensão. 2014;11(18):33.

[20] Manchur J, Suriani ALA, Cunha MC da. A contribuição de projetos de extensão na formação profissional de graduandos de licenciaturas. Rev Conex UEPG. 2013;9(2):334-41.

[21] Legey A, Jurberg C, Coutinho C. Educação científica na mídia impressa brasileira: avaliação da divulgação de biologia celular em jornais e revistas selecionados. Alexandria Rev Educ em Ciência e Tecnol. 2009;2(3):35-52.

[22] Anastasiou L das GC, Alves LP. Processos de ensinagem na universidade : pressupostos para as estratégias de trabalho em aula. 2004.

[23] Albuquerque FM de AS, Farias CR de O, Araújo MLF. O uso educativo do Júri Simulado no Ensino Médio : estratégias para o estudo de uma temática. 2013;

[24] Oliveira AS de, Soares MHFB. Juri Químico: Uma Atividade para Discutir Conseitos Químicos. Química Nov na Esc. 2005;18-24.

[25] Kist CP, Ferraz DF. Compreensão de professores de biologia sobre as interações entre ciência, tecnologia e sociedade Introdução. Rev Bras Pesqui em Educ em Ciências. 2010;10.

[26] Ribeiro RA, Santos R da S. O processo de formação de professores de Biologia e a interferência das tecnologias e mídias no ensino de Genética e Biologia Molecular. 2013;055(79):49-61. 